\title{
O Serviço Social brasileiro na entrada do século XXl: considerações sobre o trabalho profissional*
}

\section{The Brazilian Social Work at the entrance of the XXI century: considerations of professional work}

\author{
Carlos Antonio de Souza Moraes \\ Docente na UFF/ Departamento de Serviço Social de Campos, Rio de Janeiro, Brasil; doutor em Serviço \\ Social pela PUC-SP; líder do Grupo Interdisciplinar de Estudo e Pesquisa em Cotidiano e Saúde. \\ as.carlosmoraes@gmail.com
}

\begin{abstract}
Resumo: Este artigo analisa o Serviço Social brasileiro na entrada do século XXI, refletindo a respeito das mudanças do capitalismo contemporâneo e de suas implicações para o trabalho profissional. Objetiva discutir como os assistentes sociais têm se posicionado no plano teórico-prático/interventivo e ético-político/organizativo, na tentativa de enfrentar essa realidade, defender seus valores e responder, enquanto trabalhadores assalariados dotados de estatuto intelectual, às exigências impostas pela sociedade capitalista e às necessidades sociais dos sujeitos sociais.
\end{abstract}

Palavras-chave: Neoliberalismo do século XXI. Serviço Social. Trabalho profissional. Mercado de trabalho. Instituições empregadoras. Condição assalariada.

\begin{abstract}
This article analyzes the Brazilian Social Service at the entrance of the century, reflecting on the changes of contemporary capitalism and its implications for employment. It aims to discuss how social workers has positioned itself in the theoretical and practical plan / interventional and ethical-political / organizational in an attempt to address the current reality, to defend its values and respond as salaried workers with intellectual status, the requirements imposed by capitalist society and social needs of social subjects.
\end{abstract}

Keywords: Neoliberalism of the century. Social Work. Professional work. Labor market. Health organizations. Self-employed status.

* Este artigo é fruto da tese de doutorado sob o título O Serviço Social brasileiro na entrada do século XXI: formação, trabalho, pesquisa, dimensão investigativa e a particularidade da saúde, orientada pela professora Regina G. Marsiglia e defendida em março de 2016 no Programa de Estudos Pós-Graduados em Serviço Social da PUC-SP. 


\section{I-Problematização inicial}

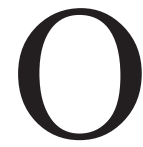

século XXI tem sido marcado pela renovação nas estratégias de "administração dos problemas sociais". Tal renovação tem se integrado à dinâmica dos países latino-americanos a partir de diretrizes criadas por organismos internacionais e se realizado em diversos ângulos e setores da sociedade, através de mecanismos políticos e ideológicos que se desenvolvem por meio das investidas do mercado e criação dos padrões de consumo (multiplicando as possibilidades de acessá-lo) e de políticas sociais, embora a centralidade esteja nas políticas de transferência de renda, colocadas como "inovadoras" ou até "revolucionárias", mas que reduzem a desigualdade social à desigualdade de renda.

A "solução para os problemas sociais" baseia-se tanto na perspectiva de responsabilização dos pobres, que são impostos à consciência moral da nação, quanto na eficiência da administração, através de um "choque de gestão", que investigue, identifique, avalie, monitore e crie estratégias de enfrentamento dos "freios" do desenvolvimento econômico.

Ao Estado, entendido por Pfeifer (2014, p. 747) como "mediador consumidor", tem cabido à tarefa de criar e garantir meios para que os sujeitos sociais comprem os bens e serviços sociais capazes de satisfazer às necessidades humanas básicas e as criadas pela sociedade do capital. Para tanto, objetiva-se criar condições e induzir indivíduos e famílias para o consumo de serviços disponibilizados por empresas privadas e instituições públicas não estatais. Assim, o governo tem respondido às dificuldades de acumulação do capital no contexto de crise por meio de estímulos ao investimento privado via expansão do crédito e redução dos custos tributários para o setor privado, entre outros.

As implicações sociais desses processos, embora sinalizadas estatisticamente no início do século XXI de forma positiva ao criar propostas que intentam articular desenvolvimento econômico ao social, têm contribuído para perpetuar a dependência externa e reproduzir a estrutural desigualdade social, em um contexto de insegurança no trabalho (através de contratos temporários e/ou com expedientes parciais, condições e relações de trabalho precarizadas e fragilidade dos vínculos de trabalho), "de ruptura entre trabalho e proteção social" (Yazbek, 2014), baixos salários, submissão às normas do mercado e metas quantitativas que, quando atingidas, denotam eficiência e competência na realização do trabalho. 
O cenário atual tem se agravado por meio do aumento do desemprego, corte dos gastos públicos, articulação ofensiva entre setor público e privado, transferindo complexos do Estado para a iniciativa privada e instituindo processos ideopolíticos que têm reconfigurado a forma de pensar e agir dos sujeitos, através de sobrevalorização do ter em relação ao ser ou, ainda, "no ter para o ser, para existir numa fábula vazia de significados". Assim, o Estado gestor, síntese das reformas neoliberais, altera veementemente a ideia de proteção social ampla e muda de forma significativa o cenário em que se encontra esse sujeito, transformando-o e alinhando-o aos interesses do capital (Martins, 2015, p. 19).

A identificação dessas análises a respeito do cenário político, econômico e social brasileiro na entrada do novo século permitiu-nos afirmar em momentos anteriores que vivenciamos uma nova fase do neoliberalismo, "o neoliberalismo do século XXI", que mantém características de sua origem (liberdade de mercado, ajuste fiscal, concepção de homem possessivo, competitivo, calculista e de sociedade como agregado fortuito, em que o indivíduo pode realizar seus propósitos privados, entre outros), mas renova suas propostas, sobretudo através da restauração do Estado e suas estratégias de intervenção na política econômica e social (Moraes, 2016).

Os impactos do "neoliberalismo do século XXI" sobre a particularidade da política de educação para o ensino superior nos anos 2000 têm sido analisados por produções acadêmico-científicas que têm indicado que, ao se pautar em diretrizes de organismos internacionais (ONU, Banco Mundial, FMI), essa política tem sido caracterizada por larga escala de expansão universitária mercantil, que aprofunda a privatização interna das universidades públicas e amplia a privatização da educação superior presencial e a distância (Dahmer, 2008), permitindo, assim, a intensificação da desqualificação da formação profissional, sob a aparência de ampliação do acesso ao ensino superior (Lima, 2008). Nesse caso, a educação move-se estrategicamente a favor da hegemonia do capital, contribuindo para ampliar o processo de superexploração do trabalho, promovido pela reestruturação produtiva (Mészáros, 2005), sofrendo, como direito e política, medidas cada vez mais regressivas, que também estão vinculadas a um ensino de manual e desprovido de criticidade.

Essa complexa realidade política, econômica, social e cultural, sinalizada de forma geral, incide sobre o Serviço Social ao repercutir nos processos de formação 
profissional que, ao tomar por base de suas análises o projeto ético-político atual, indicam uma série de influxos baseados em valores hegemônicos que deformam, precarizam, massificam e vendem o que o Serviço Social não defende como educação. Além disso, reconfiguram o mercado de trabalho, bem como as condições de inserção, permanência, relações, intensidade do trabalho, perfil e postura profissional, além de formular e formatar as políticas sociais em que esses e outros profissionais atuam, germinando novas demandas institucionais, "limitando" as respostas profissionais aos usuários e predeterminando as demandas que os usuários apresentarão e que poderão ter respostas no espaço institucional específico de trabalho do assistente social.

Diante desses apontamentos, a preocupação está em construir reflexões, a partir de pesquisa bibliográfica e de análise de realidade, a respeito de como os assistentes sociais (de forma individual e coletiva), nos primeiros anos do século XXI, têm se posicionado no plano teórico-prático/interventivo e ético-político/organizativo, na tentativa de enfrentar tal realidade, defender seus valores e responder, enquanto trabalhadores assalariados dotados de estatuto intelectual, às exigências impostas pela sociedade capitalista e às necessidades sociais dos sujeitos sociais.

\section{II - 0 trabalho do assistente social na entrada do século XXI: dilemas, desafios e tendências}

$\mathrm{Na}$ análise que se constrói, vinculada ao trabalho e ao mercado de trabalho do Serviço Social - como uma das especializações do trabalho coletivo, a partir da divisão social e técnica do trabalho - um primeiro ponto introdutório a ser destacado é que, de forma geral, é predominante a indicação de que essa profissão sofre os processos gerais de precarização do trabalho, de suas condições e relações no cenário atual. Seus vínculos trabalhistas são, muitas vezes, precários, e as exigências institucionais são crescentes, desafiando o profissional a não ser crítico, propositivo e criativo.

Essa precarização, insegurança e desproteção dos trabalhadores, entre eles os assistentes sociais, são expressas, entre outras formas, segundo Raichelis (2013, p. 626), nos processos de "terceirização e quarteirização dos vínculos trabalhistas". Há um aumento da contratação de trabalhadores por projetos temporários, desre- 
gulamentação do trabalho formal, rebaixamentos salariais, perdas de direitos trabalhistas, que geram, nas palavras de Iamamoto (2014, p. 633; grifos da autora), a "insegurança da vida dos profissionais" em virtude das dificuldades de emprego ou trabalho de largo prazo e a perda de direitos, implicando diretamente sua sobrevivência material e social.

Essas transformações do mundo do trabalho nas últimas décadas caracterizam, para Raichelis (2013, p. 617, grifos da autora), "uma nova era de precarização estrutural do trabalho", que também tem contribuído para a reedição do trabalho escravo e infantil, entre outros.

Assim, o assistente social depende da venda de sua força de trabalho para a manutenção de sua sobrevivência e, enquanto trabalhador assalariado, tem que responder às prescrições institucionais, que redesenham o caminho da burocracia, do empirismo e do imediatismo. Nesses processos, vê sua relativa autonomia ameaçada, em que se coloca em questão, sobretudo, a dimensão intelectiva do trabalho profissional na perspectiva do atual projeto ético-político do Serviço Social.

Se a dimensão intelectiva do trabalho profissional é composta pela unidade entre pensar e agir críticos, a hipótese sustentada por este estudo é de ameaça à dimensão intelectiva do trabalho profissional na perspectiva do atual projeto ético-político do Serviço Social. E embora envolva a dimensão político-profissional, por meio da construção de processos determinados pela mundialização do capital e suas incidências nos Estados nacionais, na cultura, nas políticas econômicas e sociais e nas sociedades, capazes de gerar a despolitização da categoria profissional ou sua politização à direita, conforme tem apontado Iamamoto (2014), é mais ampla, à medida que também incide sobre a dimensão teórica do trabalho profissional e se expressa claramente na dimensão técnico-operativa. Isto é, no contexto atual têm sido ameaçadas as possibilidades de aprofundamento do conhecimento, da tentativa de romper com o absolutamente visível, da pesquisa da realidade social, da intercessão entre a dimensão investigativa e interventiva, do aprofundamento das informações traduzidas na imediaticidade da realidade, da sistematização e estudo dessas informações e do planejamento crítico do trabalho profissional.

Essas ameaças decorrem de práticas reduzidas preponderantemente ao imediatismo e com fragilidades nos vínculos com os valores do projeto profissional 
atual, determinadas pelas atuais exigências do capitalismo a partir das contrarreformas do Estado e suas injunções sobre a reconfiguração das políticas e instituições sociais e nos processos de "deformação" profissional no ensino público e privado, intensificado pelo EAD nos anos 2000. Tal realidade tem capturado o sêmen do pensamento crítico dos assistentes sociais, limitando-os ao trato da realidade aparente, restrita ao senso comum e desprovida de criticidade na leitura, no diálogo e na intervenção profissional.

Esses processos não apenas podem arruinar a dimensão política, construída pelo Serviço Social a partir do Movimento de Reconceituação no Brasil (o que é extremamente grave), como, dialeticamente, agridem de forma ofensiva a leitura de realidade, a produção de conhecimentos no âmbito do trabalho profissional e a construção de intervenções que fortaleçam os interesses e projetos da classe trabalhadora, ameaçando a dimensão intelectiva do trabalho do assistente social na perspectiva do atual projeto ético-político do Serviço Social e incidindo diretamente na dimensão técnico-operativa, expressa no fazer profissional.

Assim, torna-se necessário questionar o(s) tipo(s) de conhecimento(s) que os assistentes sociais têm conseguido construir em seu trabalho profissional no século XXI. Além desse questionamento, cabe uma defesa: não basta construir conhecimentos qualificados, se despolitizados ou politizados à direita (Iamamoto, 2014). As informações e dados produzidos e analisados no contexto do trabalho profissional precisam contribuir para fazer política em defesa das classes subalternas, no sentido, apontado por Yazbek (2014), de modificar e construir outros lugares de poder, através de resistências e de alianças estratégicas por dentro dos espaços institucionais e, particularmente, no contexto das lutas sociais.

Se a condição de subalternidade, conforme aponta Yazbek (2014), nos termos de Gramsci (2002), requer a construção de novos modos de pensar, a elaboração de uma concepção de mundo crítica e coerente, necessária para ultrapassar o senso comum e contribuir para que as classes subalternas produzam contra-hegemonia, há aqui uma problemática dialeticamente complexa. Esta incide na fragilização da dimensão teórica, metodológica e política do trabalho profissional, ameaçando a capacidade de pensar a realidade social com bases firmes e seguras no projeto profissional atual, sendo materializadas na realidade através de ações pautadas no imediatismo, no bom senso, na submissão às regras, normas e mandos institucionais, que tensionam as possibilidades de autonomia do profissional, 
também confrontadas pelo fenômeno de insegurança no trabalho que atinge inclusive os assistentes sociais.

Além disso, é necessário considerar outro elemento relevante: o Serviço Social, tomado como totalidade, é maior que seu projeto ético-político-profissional, visto que, dentro de si, existem diferentes e antagônicos projetos profissionais, o que significa dizer que "ainda que goze de hegemonia, se forem consideradas suas diversas dimensões, jamais será exclusivo no âmbito da categoria profissional”, pelo fato de a categoria ser constituída por sujeitos singulares, com diferenças do ponto de vista de classe, das condições intelectuais, interesses políticos, econômicos, preferências ideológicas, dentre outros (Ortiz, 2015, p. 184).

Por outro lado, existe resistência a esses processos, seja pelas organizações do Serviço Social (CFESS, Cress, Abepss), que assumem "o caráter de intelectual coletivo" (Yazbek, 2014, p. 690), seja pelos próprios assistentes sociais em seus espaços sócio-ocupacionais. Há fluxo na veia daqueles que alimentam a cultura crítica no interior da profissão, defendendo o projeto profissional e resistindo à tendência do discurso ideológico capitalista contemporâneo, de focalização e responsabilização dos indivíduos isolados, famílias e grupos particulares por sua situação e condição de vida.

Entre os fluxos de construção e defesa do projeto profissional e os influxos de aluimento desse projeto, produzido pela sociedade e imposto aos trabalhadores, está o sujeito vivo, responsável pelo seu trabalho e dependente dele para a garantia de sua sobrevivência. Pensar o assistente social, membro dessa realidade, determinado e desempenhando um papel político e interventivo, também determinante, sobre ela é fundamental nos dias atuais.

Assim, um segundo ponto-chave, introdutório e determinante é que se torna elementar dedicar atenção à predominância feminina entre os assistentes sociais, que, segundo dados do CFESS (2005), compõe 97\% da profissão no Brasil. Além disso, a PNAD/IBGE (2013) indica que, na formação profissional, o curso de Serviço Social é o terceiro maior curso feminino do país, com 157.919 estudantes mulheres, perdendo apenas para os de Pedagogia (568.030 estudantes do sexo feminino) e Enfermagem (194.166 discentes mulheres).

Assim, a análise de sua imagem social e as discriminações impostas à mulher no mercado de trabalho devem ser apreendidas em uma perspectiva de classe social. 
Mais que isso: além de o Serviço Social ser composto por mulheres oriundas da classe trabalhadora, há a predominância de pardas ou negras. Esse também é o perfil de suas usuárias, muitas delas vítimas de violência, exclusão, discriminação no mundo privado e público (Lima, 2014).

Dessa maneira, entre as complexas mediações necessárias ao entendimento do Serviço Social nos tempos atuais, a defesa vinculada ao trabalho profissional é de que se o neoliberalismo do século XXI, apoiado na defesa do mercado e do consumo, redesenha as margens de enfrentamento da "questão social", ${ }^{1}$ sobretudo através de políticas de transferência de renda direcionadas aos pobres e miseráveis, e incentiva a participação do terceiro setor e de organizações privadas no atendimento às demandas sociais, essas questões repercutirão diretamente nas políticas sociais, no mercado de trabalho dos assistentes sociais, nos vínculos empregatícios, na formação profissional, no questionamento do projeto profissional - inclusive pela própria categoria - e na condição de trabalhador assalariado. Dessa forma, relativiza cada vez mais sua autonomia e ameaça a dimensão intelectiva do trabalho profissional na perspectiva do projeto ético-político do Serviço Social atual, o que produz drásticas implicações à dimensão teórica, metodológica, política e técnica do trabalho profissional.

Esses processos agridem o sujeito vivo, responsável pelo trabalho, levam ao seu adoecimento e ameaçam o protagonismo profissional, que só se edifica através da fecundação da capacidade crítica dos assistentes sociais. No entanto, ao serem alimentados pela segurança dos valores ético-políticos, há os que insistem em resistir a esses processos, o que torna-se razoável afirmar que é na relação direta com o usuário, através da qualificação permanente, que esses assistentes sociais - sobretudo, mas não exclusivamente - são capazes de romper os limites e ditames institucionais, revigorar sua criticidade e defender sua relativa autonomia, colocando-se como sujeito de sua ação profissional, através de leitura da realidade, inves-

1. Para Yazbek (2014, p. 683), “a 'questão social' permeia a sociabilidade da sociedade de classes e seus antagonismos constituintes. Envolve disputa social, política e cultural em confronto com as desigualdades socialmente produzidas". Além disso, há o destaque para "um tempo caracterizado por mudanças aceleradas em diferentes dimensões da vida social, por uma nova sociabilidade e uma nova política" (p. 678), com desestabilização no campo do trabalho, precarização e insegurança, interferindo nas proteções e garantias vinculadas historicamente ao emprego. 
tigação, sistematização e estudo, presentes na dimensão pedagógica do trabalho profissional (Abreu, 2004).

Nesses primeiros quinze anos do século XXI, o Serviço Social, determinado por essa realidade e insistente na defesa e crítica de seu projeto profissional, vivencia fluxos de construção e avanços, com a grande expressão da redução da carga horária de trabalho semanal para trinta horas, e influxos de desconstrução vinculados à "deformação" profissional, bem como a precarização das condições e das relações de trabalho, o que tem repercutido diretamente no perfil do assistente social do novo século.

Entre fluxos e influxos, o Serviço Social se constrói, desconstrói e reconstrói marcado por práticas conservadoras, neoconservadoras e progressistas, o que cria embates no interior da categoria, reeditando antigos dilemas no exercício da profissão e demarcando um lugar para o novo conservadorismo nos tempos atuais.

Essas práticas, ao longo dos anos 1990 e, sobretudo, início dos anos 2000, têm em comum um mesmo discurso: o "direito a ter direitos", como tentativa de enfrentar os problemas postos pela ofensiva neoliberal em fins do século XX e com sua nova roupagem no século XXI. No entanto, seu caráter (neo)conservador ou progressista tem vínculos diretos com a dimensão política. Se desprovido do sentido político construído pelo projeto profissional, significa que esse discurso contribui para a despolitização dos assistentes sociais, que, na tentativa de resultados imediatos, tentam abrandar a tensão posta na situação, contribuindo para que haja certa conformação do usuário ao acessar seu direito ou ter essa possibilidade (Guerra, 2004; Gomes, 2013).

Ao participar desses processos, deve ser alvo de reflexão a compreensão que se tem a respeito dos efeitos da produção ideológica sobre as práticas sociais na elaboração de visão de mundo, pertencimento de classe, lutas coletivas dos sujeitos sociais e movimentos de resistência, já que há uma tendência de responsabilização exclusiva dos sujeitos e de suas famílias por sua situação de vida. Isso porque os dispositivos institucionais não dão conta das necessidades sociais dos sujeitos, burocratizando as práticas e trabalhando com pequenas doses de inclusão (Faleiros, 2013).

Para Gomes (2013, p. 107), no entanto, "a cultura profissional acaba absorvendo o discurso ideológico contemporâneo, que tenta, a todo custo, suprimir a perspectiva de classe e as possibilidades de construção de uma nova cultura". Assim, 
o engenhoso desafio que se coloca é o da defesa da democracia burguesa em substituição à luta anticapitalista, o que ameaça brutalmente a perspectiva crítica que intenta o desenvolvimento da luta emancipatória.

Aliás, a defesa da luta emancipatória tem por base o legado do Movimento de Reconceituação do Serviço Social no Brasil, especialmente a partir da "intenção de ruptura" (Netto, 2005), e a construção e defesa do Projeto Ético-Político Profissional atual. Este pode se realizar nas seguintes dimensões no universo da profissão: nos seus instrumentos legais, que asseguram direitos e deveres desses profissionais e defendem a autonomia profissional na condução do seu trabalho; nas expressões da categoria e manifestações coletivas, através dos Conselhos Federal e Regionais de Serviço Social (CFESS, Cress), da Associação Brasileira de Ensino e Pesquisa em Serviço Social (Abepss), que se posicionam política e publicamente em face da realidade em que vivemos, das expressões da "questão social", do Estado, sociedade, políticas públicas e demais profissões e que, conforme Yazbek (2014), articulam e organizam a presença dos assistentes sociais em lutas coletivas na direção da construção de outra ordem societária; na articulação com outras profissões, movimentos sociais e entidades internacionais de Serviço Social; no trabalho profissional, na defesa da qualidade dos serviços prestados, fortalecimento dos direitos dos usuários e a defesa de uma nova sociabilidade, através da construção de uma prática baseada na perspectiva crítico-dialética, por meio do cultivo da pesquisa e da dimensão investigativa, que afiançam a busca do saber-fazer, ancorados no tipo de sociedade que se deseja; no ensino universitário, em nível de graduação e pós-graduação, responsável pela qualificação, formação teórica e construção de um perfil profissional dotado de estatuto intelectual. Nesse caso, há a afirmação e defesa das Diretrizes Curriculares de 1996 para o curso de Serviço Social e a luta crítica à contrarreforma universitária, que tem mercantilizado a educação, desqualificando a formação profissional. Além disso, há a defesa da autonomia e presença política do movimento estudantil no Serviço Social (Iamamoto, 2011).

Com base na atual dimensão ético-política do Serviço Social, as estratégias que tentam responder e enfrentar a questão social têm sido tensionadas por projetos político-institucionais distintos, que são indissociáveis da contrarreforma do Estado, via redução dos cortes orçamentários para o atendimento das demandas dos sujeitos e burocratização da vida social, que produzem implicações diretas às condições 
de trabalho e relações sociais em que estão inscritos os assistentes sociais. Essas condições e relações interferem no direcionamento do trabalho, nas atribuições veiculadas aos assistentes sociais, nos recursos para o trabalho, que repercutem em seu conteúdo e qualidade. Além disso, são estabelecidos requisitos de produtividade e eficiência, além de prazos e rotinas a serem observados no desenvolvimento da atividade profissional.

Assim, os profissionais, muitas vezes com vínculos temporários e, sobretudo, precários de trabalho, precisam se desdobrar para administrar processos, protocolos gerais de aplicação de medidas, a falta de recursos governamentais, além de estudar a história de seus usuários, mesmo sem muitas perspectivas de alcançar sua inclusão na política em que atuam (Faleiros, 2013).

Dessa maneira, impõem-lhes condicionantes socialmente objetivos à condução de seu trabalho, exigindo adequação aos parâmetros institucionais e uma diversidade de ações que tenham por características a burocracia, a espontaneidade, o bom senso e o empirismo, não havendo, para o capitalismo, a necessidade de uma definição muito clara do papel que o Serviço Social deva cumprir (Idem).

Nesses processos, constrói-se, por parte das instituições contratantes, uma relação esquizofrênica entre profissional com formação generalista, compreensão ampliada dos fenômenos sociais e ações direcionadas ao campo social capaz de solucionar, no plano imediato, os diferentes problemas sociais manifestos no cotidiano institucional, mesmo que rompam os domínios de suas atribuições. Há a compreensão de que fenômenos sociais dotados de questões objetivas e subjetivas devem ser objeto de intervenção dos assistentes sociais, que são capazes de tratá-los com verniz humanitário e solidário, embora deva focalizar suas ações e discursos na responsabilidade dos sujeitos e da família pelas demandas apresentadas.

É recorrente, dessa forma, sobretudo em municípios de pequeno porte, uma maior polivalência no que se refere às demandas direcionadas ao assistente social (Iamamoto, 2014), que também contribuem na intensificação das possibilidades de alienação profissional, distanciando-o de seu projeto de profissão através de uma tensão com sua condição de trabalhador assalariado, ameaçando a dimensão intelectiva do trabalho na perspectiva do Projeto Ético-Político Profissional.

Assim, com uma limitação dos recursos institucionais para acionar a defesa dos direitos e meios de acessá-los, são alterados os processos, condições e demandas 
do exercício profissional, que são respondidas com doses pontuais de inclusão e redução de danos, responsabilizando, sobretudo, os sujeitos.

Inseridos e acorrentados a esses processos por vários momentos, o trabalho do assistente social passa a expressar uma forma modernizada do antigo conservadorismo profissional, através de ampliação do mercado de trabalho, conquista de novas funções e cargos no interior das instituições. Por outro lado e como fruto dessa mesma realidade, isso ocorre por meio da redução de sua autonomia e de sua submissão aos ditames institucionais.

Isso se deve ao fato de que o assistente social ingressa na instituição empregadora integrando um grupo de trabalhadores que desenvolvem as ações institucionais. As prioridades do trabalho, o modo de operá-lo e de acessar os recursos necessários são frutos do poder institucional, em suas formas de organização, com destaque para o recorte das políticas, classificação dos problemas e controle dos recursos. Por parte da instituição, o objetivo central é a produtividade e a eficiência, baseadas em critérios quantitativos, com o mínimo de recursos para a população sobreviver. Dessa maneira, Faleiros (2013) acrescenta que o aparato institucional associa responsabilização dos sujeitos individuais e de suas famílias com reduzido suporte institucional público.

Nessas situações, os segmentos subalternos apresentam suas demandas aos assistentes sociais como problemas sociais, frutos de conflitos que expressam necessidades humanas a partir da luta por sobrevivência, advindas de condições de doença, pobreza, violência, discriminação, desemprego, marcados por rótulos e sentimentos de incapacidade, fracasso e derrota, além de longos caminhos percorridos em frustrantes tentativas de acesso ao que lhes é resguardado constitucionalmente como direito. No plano imediato, a busca pelo Serviço Social é a busca de respostas "que solucionem seus problemas" individuais. Mais profundamente, expressa a realidade de sujeitos que se encontram em lugar de explorados, com trajetórias de não acesso à distribuição de riqueza e poder, e em uma relação de forças que os restringe, tornando-os sem vez e sem voz.

É nessa tensão, entre o "peso do poder institucional” (Iamamoto, 2011) e as necessidades sociais dos segmentos subalternos, que o assistente social constrói o seu trabalho, na formulação e execução das políticas, na articulação de dispositivos de distribuição de benefícios, através da informação, encaminhamento, orientação, mobilização, tendo o desafio de decifrar, criticar e agir em uma situação concreta (Faleiros, 2013). 
Em instituições privadas, essa seletividade é estabelecida segundo critérios de seus mantenedores, através de seus interesses privados, o que diferencia o trabalho profissional no interior dessas instituições, por mais que sejam idênticos aos construídos nas instituições públicas. A lógica é a do interesse privado, alternando os significados do trabalho e o nível de abrangência (Iamamoto, 2011).

A lógica capitalista e institucional em estabelecimentos públicos e privados vincula competência a domínio burocrático, expresso no culto à autoridade e na obediência passiva às normas e rotinas institucionais. Nessa lógica, o profissional competente é aquele que se propõe a cumprir, sem questionamentos, a administração de protocolos e falta de recursos, o trato das demandas como um fim em si mesmas, despidas de mediações e revestidas de metas organizadas pelos programas. No entanto, ao operacionalizar esses procedimentos, o profissional também demonstra certa preocupação com os usuários, via caráter humanitário construído pelo ideário capitalista e até religioso, que reforçam a solidariedade e os valores moralizadores da vida social. Assim, os assistentes sociais se tornam cada vez mais enrijecidos pelo trabalho burocrático e pela administração de medidas gerais (presentes na política de assistência social), além de realizarem o atendimento e a prestação de serviços individuais ou grupais. Neste último caso - que não é uma exclusividade brasileira -, com tendência à construção de práticas psicoterapêuticas, sobretudo na área de saúde mental.

Mediante essa realidade, é necessário que os assistentes sociais e trabalhadores de modo geral articulem alianças no cotidiano para, inicialmente, questionar o poder no interior das instituições, bem como o processo institucional fragmentado e interpessoal que subordina e desqualifica o usuário (Faleiros, 2013). A partir dessas reflexões e mais amplamente, torna-se fundamental que se mobilizem no questionamento da ordem social, tendo por base análises sobre a raiz da desigualdade social.

O desafio é considerar as relações de poder instituídas e em fase de se instituir, as que questionam o poder, por mediações de saber, de alianças que invistam no caráter organizativo e político de resistência (Faleiros, 2013). A compreensão dessa tensão, movida por um terreno arenoso, é a pedra angular no desenvolvimento do trabalho profissional. Para tanto, o assistente social deve contar com uma formação acadêmica de qualidade, compreensão, consciência e segurança dos princípios ético-políticos de seu projeto de profissão, que o 
capacite à leitura crítica da realidade e à criação de estratégias que contribuam para manutenção de seu vínculo empregatício e, ao mesmo tempo, garantidoras de sua relativa autonomia profissional.

Parte-se, assim, da compreensão de que o Serviço Social do século XXI tem o desafio de construir a análise macrossocietária do mercado de trabalho e das condições de trabalho e suas implicações para o trabalho profissional assalariado, mas defende-se que, complementar a tais estudos, é necessária a análise institucional.

Segundo Sampaio e Oliveira (2014), as instituições, como um fenômeno não natural, resultado das relações de classe e dos embates delas decorrentes, requerem reflexão a respeito de sua existência e seus efeitos específicos em seu interior e em relação à sociedade capitalista. Assim, para o entendimento da profissão e da problematização de possíveis estratégias profissionais, nos diferentes espaços sócio-ocupacionais, também é necessário analisar as instituições em que ela é exercida.

Ainda para os autores, a análise institucional deve ser assumida como uma técnica para o trabalho, capaz de alimentar, a partir de dimensões teóricas, éticas e políticas, a dimensão técnica do trabalho profissional, por meio de procedimentos necessários ao trabalho do assistente social que viabilizem a identificação dos determinantes causais da realidade institucional e a configuração do mercado de trabalho.

Dessa maneira, referimo-nos à defesa de um profissional que busca imprimir nortes ao seu trabalho, afirmando-se como sujeito profissional. No entanto, sabe-se que esse não é um simples compromisso, fruto, apenas, da intenção do profissional de construir o Serviço Social que se deseja. Para além das dimensões já abordadas ao longo do artigo, também é importante a postura do profissional no interior das instituições, o diálogo que estabelece com a chefia, profissionais, funcionários e usuários. É fundamental o entendimento de que cada fala ou ação pode aproximar ou afastar os sujeitos, gerar ou não a possibilidade de vínculo, afetando e produzindo resultados no trabalho profissional. O sentimento de confiança é fruto de todos esses processos, advindos de um trabalho de observação não só do profissional para com a realidade em que trabalha, mas da realidade viva em relação ao sujeito profissional. 
O estudo da realidade, o planejamento crítico do trabalho, os posicionamentos seguros e firmes mediante situações adversas, o domínio da legislação em vigor a partir de dimensões teóricas, sócio-históricas e ético-políticas contribuem para o respeito às defesas desses profissionais e para ultrapassar a compreensão de que o preenchimento de um formulário de atendimento é apenas um ritual burocrático a ser cumprido. $\mathrm{O}$ fato da necessidade de sua realização também pode contribuir para a aproximação dos sujeitos sociais, conhecimento de suas demandas, aprofundamento das questões pertinentes ao trabalho profissional, sistematização desses dados, análise e criação de estratégias de enfrentamento na perspectiva ético-política profissional atual.

Operacionalizar políticas coloca o profissional frente a frente com a realidade, desafio e vantagem histórica do Serviço Social. Portanto, aproxima o assistente social de uma competência crítica vinculada a critérios qualitativos, diferente daquela compreensão de competência da sociedade burguesa. E o que tem sido feito no que diz respeito a esses processos? Tem-se analisado as relações entre situações singulares e processos macroscópicos? Tem-se buscado compreender as causas e possíveis significados da gama de informações coletadas cotidianamente? Como potencializar as ações e estimular a participação dos sujeitos sociais na defesa de acesso e respeito a seus direitos humanos? Como contribuir para a construção de ações mobilizadoras, de resistência, capazes de produzir a contra-hegemonia?

No movimento inverso ao que a realidade impõe, há um compromisso ético-político assumido com uma profissão, que requisita um perfil profissional culto, crítico, capaz de analisar os momentos de avançar na defesa de seu projeto de profissão e sociedade, porque estuda a sociedade, investiga as situações imediatas, decifra as situações singulares, potencializando suas ações.

Sabe-se dos grandes entraves enfrentados na tentativa de construir ações transformadoras em uma sociedade com traços conservadores (Faleiros, 2013). Como já vem sendo sinalizado (Moraes, 2015), essa proposta exigirá não apenas o conhecimento do projeto de profissão, mas também a habilidade do profissional, pois, ao deixar de ser instrumento submisso da instituição empregadora e se colocar na condição de sujeito de suas ações, o profissional rompe com uma zona de conforto, que demandará posicionamentos críticos direcionados à mobilização e ao acesso, com qualidade, dos usuários aos serviços, através das políticas, mas também 
para a manutenção de seu contrato de trabalho, enquanto trabalhador assalariado. Não que seja plenamente confortável cumprir protocolos de atendimento, administrar a falta de recursos, operacionalizar instrumentos burocráticos, realizar muitos atendimentos diariamente e cumprir prazos e normas institucionais. Mas enfrentar com fundamentação teórico-crítica e capacidade criativa, conhecimento de realidade e propostas inovadoras articuladas a outros profissionais, avaliando momentos de avanços e recuos, denota um protagonismo ao e do profissional, que o faz romper as margens do desenho institucional que garante um espaço mais confortável àqueles que se inscrevem na relação de mando e obediência.

Essas ações são direcionadas a consumidores de serviços e que se constituem como sujeitos políticos e de direitos, capazes de se articular politicamente na tentativa de enfrentamento às suas questões, compartilhando depoimentos que denotam suas fragilidades, experiências de classe e histórias singulares, muitas vezes marcadas por sofrimentos diversos, mas também pela luta por direito e dignidade (Faleiros, 2013).

Assim, é fundamental o conhecimento do modo e estilo de vida, das estratégias de sobrevivência, das relações, dos desejos políticos e sociais desses sujeitos, criando um acervo de informações, depoimentos e dados capazes de gerar estudos e análises que fundamentem os posicionamentos éticos e políticos profissionais nas relações com a chefia e demais profissionais. Essa proposta envolve uma prática crítica que indaga o "por que" para trabalhar o "como", sendo necessário romper com o imediatismo, captando as posições em confronto (como o usuário, o profissional, a instituição e o contexto interpretam o real), compreendendo como as questões se constroem, trabalhando a rede de relações complexas, analisando e refletindo as relações implicadas na intenção da ação e na própria ação (Faleiros, 2013).

Esse processo exige trabalhar permanentemente a mediação, compreendendo a inseparabilidade entre reflexão e ação e encarando o desafio da construção de conhecimentos críticos com conhecimentos operativos. Nesse sentido, a pesquisa e a dimensão investigativa devem ser constitutivas do trabalho profissional (Moraes, 2013), na medida em que impulsionam o saber pensar e o saber fazer, "na defesa intransigente dos direitos humanos", no "reconhecimento da liberdade" e no "empenho na eliminação de todas as formas de preconceito" (Cfess, 2005, p. 16), enfrentando cotidianamente o racismo, a homofobia, o machismo, 
que se manifestam na realidade, desconstruindo um discurso dominante e segregador, através de um movimento dialético em que não estão separados o singular, o particular e o geral.

Ao trabalhar a elaboração reflexiva das demandas, a estratégia de socialização das informações deve ser apreendida na ótica do direito e no reconhecimento dos sujeitos coletivos e de suas necessidades, levando à reflexão e crítica entre profissional e usuário (Iamamoto, 2011). Dessa forma, as reais implicações das demandas se tornariam transparentes, conduzindo a intervenção na tentativa de inclusão às políticas, rompendo com uma perspectiva culpabilizadora e punitiva e buscando compreender as determinações de suas situações pela sociedade e suas expressões nas relações sociais singulares dos sujeitos, com repercussões no interior de suas famílias e nos espaços em que vivem.

\section{III-Algumas considerações e recomendações}

Diante da racionalidade burguesa em curso, em suas diversas formas de manifestação, assinalam-se as ameaças ao Serviço Social crítico, sobretudo com as interferências diretas sobre uma formação profissional regida pela lógica do mercado, que incentiva os cursos particulares centrados no ensino e os cursos a distância, precariza a universidade pública e dissociam ensino, pesquisa e extensão, sendo uma formação fragmentada que ameaça a dimensão intelectiva do trabalho profissional na perspectiva do atual Projeto Ético-Político do Serviço Social. Tais fatos repercutem na despolitização dos assistentes sociais e em intervenções profissionais marcadas pela insegurança no trabalho e pela condição de assalariado, tornando cada vez mais limitadas à lógica e poder institucional e desprovidas de criticidade.

Dessa forma, defendemos que a reflexão que indaga a realidade, as relações, os processos e estruturas sociais e a própria forma de pensar a seu respeito e intervir em suas causas e consequências deve ser desabrochada ao longo da formação profissional e manter-se viva e ativa na trajetória de vida e trabalho do assistente social. Reconstruir posicionamentos baseados no projeto profissional e reafirmar sua identidade atual, em um contexto de ofensiva vinculada a medidas reacionárias e conservadoras que tem atacado os direitos e conquistas dos trabalhadores, além 
de grandes cortes nos orçamentos das políticas sociais públicas, é um grande desafio do Serviço Social na entrada do novo milênio. Esse desafio tem sido enfrentado por meio das seguintes estratégias no contexto atual:

1. Em relação à formação profissional: a) na defesa pelo acompanhamento e estudo dos processos sociais e na produção crítica de conhecimentos relativos aos mesmos; b) na articulação entre os cursos de pós-graduação e com entidades do Serviço Social críticas à lógica produtivista e de "deformação" profissional em âmbito nacional e internacional; c) na organização de seminários, encontros e congressos que problematizem e debatam a "contrarreforma" do Estado e as implicações para a sociedade, as políticas sociais, o mercado de trabalho, os processos de trabalho, o trabalho profissional, as profissões de forma geral e a particularidade do Serviço Social, entre outros.

2. Em relação ao trabalho, na defesa: a) do estudo da realidade e da construção do conhecimento crítico no interior da categoria; b) do planejamento do trabalho, escuta qualificada e posicionamentos profissionais seguros e críticos ancorados na dimensão ético-política atual; c) na elaboração reflexiva das demandas, articulando criticamente pesquisa, dimensão investigativa e dimensão interventiva; d) na articulação de alianças com outras profissões, trabalhadores e movimentos sociais.

3. No que se refere às entidades da categoria: a) na defesa do ensino universitário pautado no projeto de formação profissional atual; b) na defesa dos instrumentos legais da profissão; c) na luta por condições adequadas de trabalho, respeito profissional, concurso público e salários dignos.

Também é preciso chamar a atenção para o fato de que o Serviço Social é impensável sem as instituições, trazendo a necessidade de se elaborar estudos a respeito do trabalho no âmbito das políticas sociais e, conforme Sampaio e Oliveira (2014), de reatualizar o debate da análise institucional como uma técnica para o trabalho articulada à análise macrossocietária. Estudos que reconheçam, segundo Iamamoto (2011), as repercussões dos condicionantes sociais dispostos sobre o Serviço Social e que ultrapassem a vontade de seus agentes individuais, articulados à compreensão de que a profissão é fruto dos sujeitos que a constroem coletivamente, forjando respostas profissionais. 
Nestes casos, é fundamental afirmar que as estratégias vinculadas ao campo profissional devem pautar-se pela construção de alianças no âmbito da formação e do trabalho. Alianças que admitam que devemos nos reconhecer como trabalhadores, trazendo a necessidade da atuação conjunta. "Todos somos trabalhadores, lutamos por causas comuns, e das diferenças de nossas profissões é que devem brotar as possibilidades" (Martinelli, 1998, p. 150).

Assim, se temos o desafio profissional de estabelecer ações voltadas para o coletivo sob a ótica do controle e da ampliação de espaços para participação social, essas estratégias precisam associar-se a outras que objetivem ultrapassar as margens institucionais e profissionais e se articular à luta de classes e a movimentos sociais mais amplos, por meio de construções coletivas conscientes de sua força e com clareza em suas propostas políticas direcionadas à construção de uma nova ordem social, sem dominação/exploração de classe, etnia e gênero.

Recebido em 22/3/2016 - Aprovado em 3/6/2016

\section{Referências bibliográficas}

ABREU, M. M. A dimensão pedagógica do Serviço Social: bases histórico-conceituais e expressões particulares na sociedade brasileira. Serviço Social \& Sociedade, São Paulo, ano XXV, n. 79, especial 2004.

CFESS. Assistentes sociais no Brasil: elementos para o estudo do perfil profissional. CFESS, Brasília, maio 2005.

FALEIROS, V. de P. Globalização, correlação de forças e Serviço Social. São Paulo: Cortez, 2013.

GOMES, C. Em busca do consenso: tendências contemporâneas no Serviço Social — radicalidade democrática e afirmação de direitos. Rio de Janeiro: Lumen Juris, 2013.

GRAMSCI, A. Cadernos do cárcere. Tradução Carlos Nelson Coutinho com a colaboração de Luiz Sergio Henriques e Marco Aurélio Nogueira. Rio de Janeiro: Civilização Brasileira, 2002. v. 5. 
GUERRA, Y. O discurso do direito a ter direitos. In: ENPESS, 10., Crise contemporânea, emancipação política e emancipação humana. Recife, UFPE, 2004. [CD-ROM.]

IAMAMOTO, M. V. A formação acadêmico-profissional no Serviço Social brasileiro. Serviço Social \& Sociedade, São Paulo, n. 120, p. 609-639, out./dez. 2014.

. Serviço Social em tempo de capital fetiche: capital financeiro, trabalho e questão social. 6. ed. São Paulo: Cortez, 2011.

LIMA, R. de L. de. Formação profissional em Serviço Social e gênero: algumas considerações. Serviço Social \& Sociedade, São Paulo, n. 117, p. 45-68, jan./mar. 2014.

MARTINELLI, M. L. Uma abordagem socioeducacional. In: . O uno e o múltiplo nas relações entre as áreas do saber. 2. ed. São Paulo: Cortez, 1998.

MARTINS, V. O trabalho do assistente social no fio da navalha: a cena das aparências e a performatividade. Tese (Doutorado em Serviço Social) — Pontifícia Universidade Católica, São Paulo, 2015. 208 f.

MÉSZÁROS, I. A educação para além do capital. São Paulo: Boitempo, 2005.

MORAES, C. A. de S. A “viagem de volta": significados da pesquisa na formação e prática profissional do assistente social. Serviço Social \& Sociedade, São Paulo, n. 114, p. 240-265, abr./jul. 2013.

. A particularidade da dimensão investigativa na formação e prática profissional do assistente social. Serviço Social \& Sociedade, São Paulo, n. 122, p. 294-316, abr.jun. 2015. . O Serviço Social brasileiro na entrada do século XXI: formação, trabalho, pesquisa, dimensão investigativa e a particularidade da saúde. Tese (Doutorado em Serviço Social) — Pontifícia Universidade Católica, São Paulo, 2016. 318 f.

NETTO, J. P. O movimento de reconceituação 40 anos depois. Serviço Social \& Sociedade, São Paulo, n. 84, p. 5-20, nov. 2005.

ORTIZ, F. G. Projeto profissional, formação e estágio supervisionado em Serviço Social. In: FORTI, V.; GUERRA, Y. (Orgs.). Projeto Ético-Politico do Serviço Social: contribuições à sua crítica. Rio de Janeiro: Lumen Juris, 2015. (Coletânea Nova de Serviço Social.)

PFEIFER, M. O “social” no interior do projeto neodesenvolvimentista. Serviço Social \& Sociedade, São Paulo, n. 120, p. 746-766, out./dez. 2014. 
RAICHELIS, R. Proteção social e trabalho do assistente social: tendências e disputas na conjuntura de crise mundial. Serviço Social \& Sociedade, São Paulo, n. 116, p. 609-635, out./dez. 2013.

SAMPAIO, S. S.; OLIVEIRA, R. de. Análise institucional ontem e hoje: indicações pertinentes ao fazer profissional. Sociedade em Debate, Pelotas, v. 20, n. 2, p. 119-144, 2014.

YAZBEK, M. C. A dimensão política do trabalho do assistente social. Serviço Social \& Sociedade, São Paulo, n. 120, p. 677-693, out./dez. 2014. 